\title{
Controller Design of UPQC for Enhancing Power Quality in Distribution System
}

\author{
Kittaya Somsai \\ Department of Electrical Engineering, Faculty of Industry and Technology, Rajamangala University of Technology Isan, \\ Sakon Nakhon Campus, Thailand
}

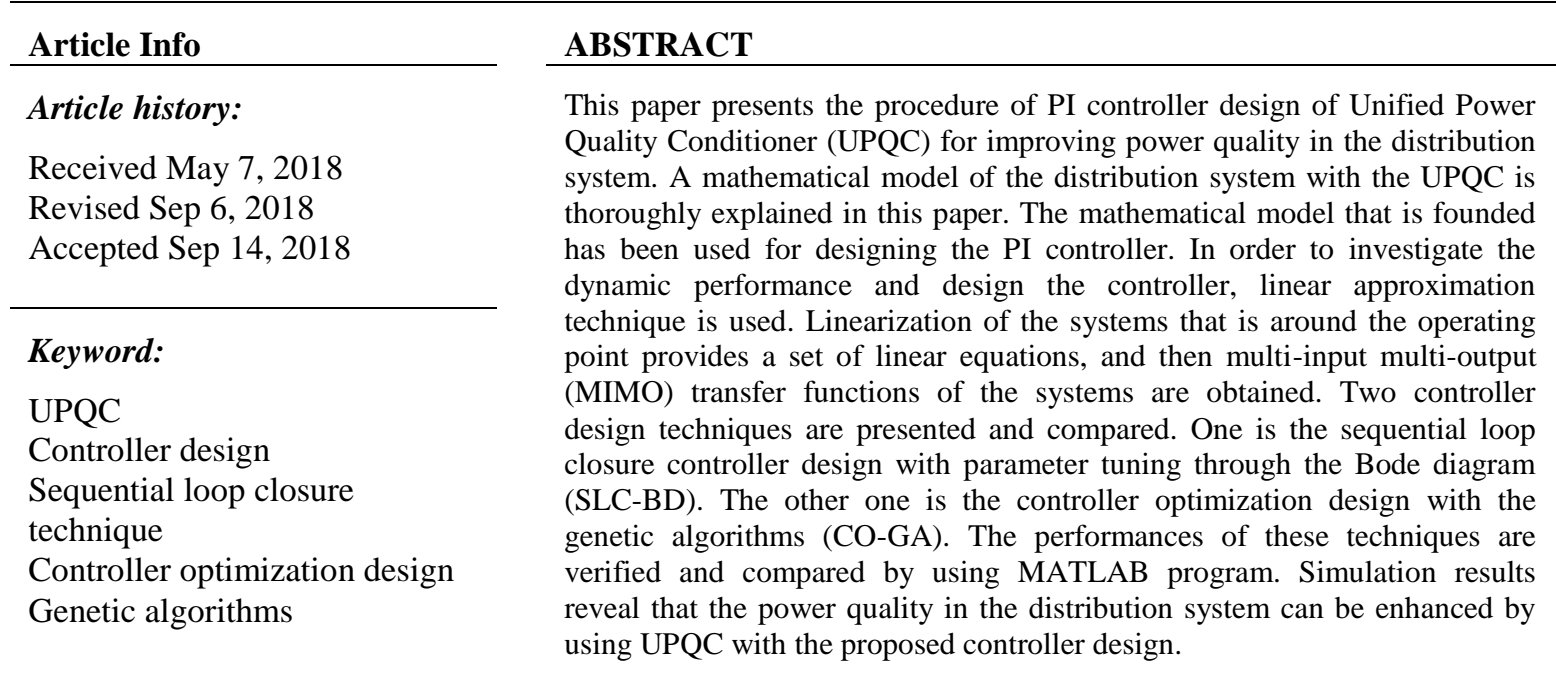

Copyright $@ 2018$ Institute of Advanced Engineering and Science. All rights reserved.

\section{Corresponding Author:}

Kittaya Somsai,

Department of Electrical Engineering,

Faculty of Industry and Technology,

Rajamangala University of Technology Isan, Sakon Nakhon Campus, 47160, Thailand.

E-mail: somsai_kittaya@yahoo.com

\section{INTRODUCTION}

In the recent times, the power distribution system has become highly complicated. It is connected with nonlinear loads such as electric welders, adjustable speed drives, and switching power supplies. These loads are the most important cause of serious problems in the power distribution system called power quality (PQ) problems. The PQ problems, known as harmonics, voltage sag/swell, flicker, and imbalance have become serious concerns and the PQ should be improved [1]. Custom power devices (CPDs) have been used increasingly in the distribution system because they can compensate several major PQ problems [2]. Unified power quality conditioner (UPQC) is one of the most crucial CPDs since it can serve various types of compensation, namely active filtering, load balancing, power factor correction, and voltage regulation [3]. Therefore, the UPQC has been interested in the field of power distribution to improve the power quality in the distribution system. The UPQC is a combination of two solid state voltage source converters (VSCs): series and shunt converter. They are connected to a common DC link capacitor, and each converter is coupled to the AC line though a transformer as shown in Figure 1. The UPQC can be used to eliminate the current harmonics by injecting a current into the system [4]. In addition, the UPQC can insert a series voltage to add the voltage at the point of common coupling (PCC) such that the device can be used to eliminate any voltage sag/swell or flicker [5]. It is also compatible with both active filtering and voltage regulation modes at the same time, which is an advantage for UPQC. 


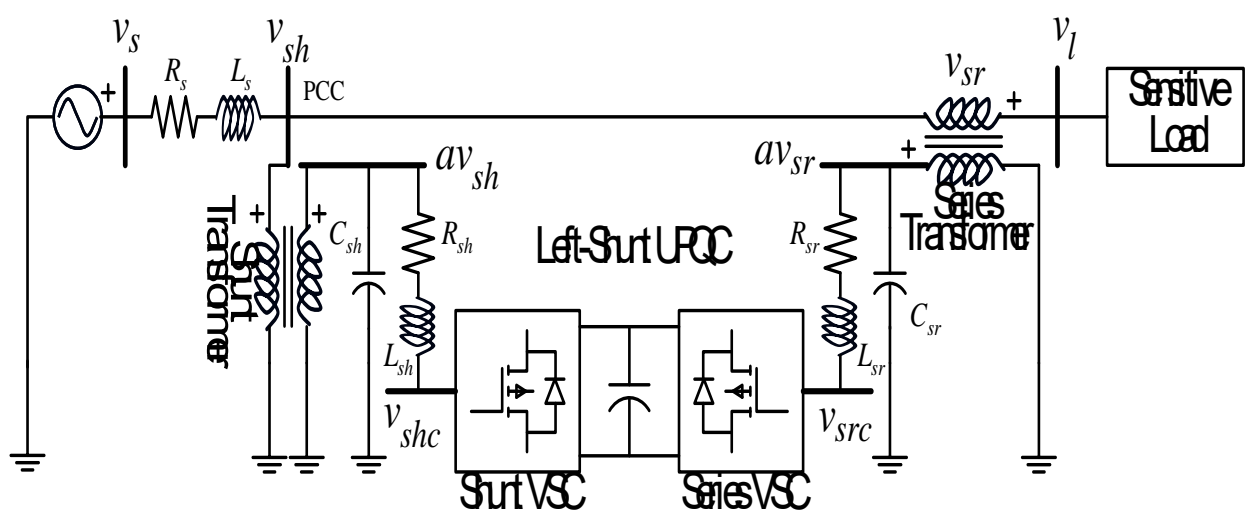

Figure 1. Schematic diagram of left-shunt UPQC

The steady state characteristics and performance of the UPQC have been investigated and reported in many researches. In [6], a steady state power flow analysis of UPQC by using MATLAB / Simulink in order to verify the analysis is proposed. The determination optimal location and sizing of UPQC in distribution networks by applying differential evolution (DE) algorithm is proposed in [7] in which the reducing of power and energy losses, improve voltage profile, decrease lines currents, and minimize installation cost are used to produce the objective function. Meanwhile, the study of control strategy of the UPQC for improving the PQ in distribution system has been widely interested. In [8], the UPQC with series and shunt compensators using two controllers, PI and Fuzzy controllers, are presented and compared. Similarly, a PI and fuzzy logic controllers of the UPQC for PQ improvement by reducing the distortions are studied and compared in [9]. Although the results shows that the UPQC with fuzzy logic controller is faster in response than PI controller, the PI controller is easier and simpler to be implemented and rea sonably effective. Moreover, the UPQC with the PI controller is easier to prove the stability of control system than fuzzy logic controller. From the reasons mentioned above, the PI controller is considered as an important device in UPQC control strategy.

In general, the control strategies based on PI controller are used in outer loop and the hysteresis current controls are used in inner current loop of the UPQC [10]-[11]. The performances of PI controllers depend on the operating points of the system. However, PI controller designed for one operating point giving a good performance may be poor for other operating points. Unfortunately, the time duration of PQ compensation in distribution system by using UPQC might take a few cycles. Therefore, PI controller design and tuning need a precise mathematical model of the distribution system with UPQC [12] in order to prevent the problems mentioned. The PI controller of the UPQC should be carefully designed and tuned. This paper presents the details of the mathematical model and controller design of the UPQC for voltage control and power factor control in distribution system. The proposed mathematical model has been used to design the controller. Moreover, the linearization [13] of the systems around the operating point is applied and then MIMO transfer functions of the systems are obtained. Two controller design techniques such as the conventional SLC-BD [14] and CO-GA are used to design the PI controllers of the UPQC. The performances of these techniques are verified and compared by using MATLAB program.

\section{MODELING OF DISTRIBUTION SYSTEM WITH UPQC}

In this paper, the distribution system with left-shunt UPQC is presented. Schematic diagram of the distribution system including with left-shunt UPQC is shown in Figure 1. In this figure, the UPQC is installed to the system before the load to protect a sensitive load from source voltage sag/swell, flicker, and distortions. In addition, it can be making the source currents and voltages sinusoidal, balanced and in phase with each other at the same time. The UPQC consists of two VSCs that they are connected back to back with a common DC link voltage. One VSC is shunt converter connected to the system through shunt transformer at PCC while the other as series converter. The series converter is connected to the system with series transformer between the PCC and the load. The equivalent circuit of the distribution system including with left-shunt UPQC is shown in Figure 2. As can be seen in this figure, the load is modeled by a parallel of resistance and inductance. For simplification, it assumes that the source, load, and UPQC are balanced. In addition, the transformer ratio of both shunt and series transformer are assumed $1(a=1)$. Under these 
assumptions and applying the $a b c$-to- $d q 0$ transformation that zero sequence components are neglected, the mathematical model of the system can be described as following.

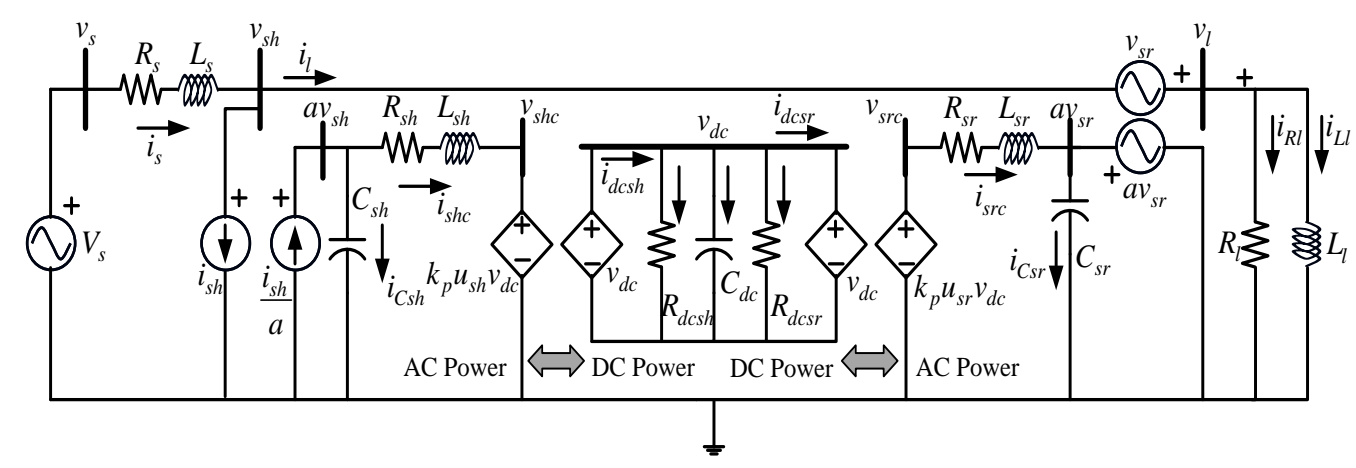

Figure 2. Equivalent circuit of the distribution system with left-shunt UPQC

\subsection{Equations at the shunt VSC side}

$$
\begin{aligned}
& \frac{d i_{s d}}{d t}=-\frac{R_{s}}{L_{s}} i_{s d}+\omega i_{s q}-\frac{1}{L_{s}} v_{s h d}+\frac{V_{s}}{L_{s}} \cos (\alpha) \\
& \frac{d i_{s q}}{d t}=-\frac{R_{s}}{L_{s}} i_{s q}-\omega i_{s d}-\frac{1}{L_{s}} v_{s h q}-\frac{V_{s}}{L_{s}} \sin (\alpha) \\
& \frac{d v_{s h d}}{d t}=-\frac{1}{C_{s h}} i_{l d}+\frac{1}{C_{s h}} i_{s d}-\frac{1}{C_{s h}} i_{s h c d}+\omega v_{s h q} \\
& \frac{d v_{s h q}}{d t}=-\frac{1}{C_{s h}} i_{l q}+\frac{1}{C_{s h}} i_{s q}-\frac{1}{C_{s h}} i_{s h c q}-\omega v_{s h d} \\
& \frac{d i_{s h c d}}{d t}=-\frac{R_{s h}}{L_{s h}} i_{s h c d}-\frac{1}{L_{s h}} v_{s h c d}+\frac{1}{L_{s h}} v_{s h d}+\omega i_{s h c q} \\
& \frac{d i_{s h c q}}{d t}=-\frac{R_{s h}}{L_{s h}} i_{s h c q}-\frac{1}{L_{s h}} v_{s h c q}+\frac{1}{L_{s h}} v_{s h q}-\omega i_{s h c d}
\end{aligned}
$$

where $i_{s d}$ and $i_{s q}$ represent the source currents in $d$ and $q$ axes that they flow from the source to PCC though the source resistor and inductor $\left(R_{s}\right.$ and $L_{s}$ ). The $v_{s h d}$ and $v_{s h q}$ are the voltages at PCC in $d$ and $q$ axes whereas the shunt VSC output currents in $d$ and $q$ axes are represented by $i_{\text {shcd }}$ and $i_{\text {shcq }}$, respectively. The $R_{s h}, L_{s h}$ and $C_{s h}$ represent RLC filter of the shunt VSC. While, the output voltages in $d$ and $q$ axes of shunt VSC are represented by $v_{\text {shcd }}$ and $v_{\text {shcq }}$, respectively. The shunt VSC output voltage can be controlled by the control signal that the $v_{\text {shcd }}$ and $v_{\text {shcq }}$ can be expanded by $v_{\text {shcd }}=k_{p} u_{\text {shd }} v_{d c}$ and $v_{\text {shcq }}=k_{p} u_{\text {sh }} v_{d c}$. Where $k_{p}$ is a constant value of the converter while $u_{s h d}$ and $u_{s h q}$ are the control signals and $v_{d c}$ is the UPQC DC voltage.

\subsection{Relation between $\mathrm{AC}$ and $\mathrm{DC}$ power}

The power flow into the shunt and series VSCs equal to the instantaneous power of the DC link which can be described as 


$$
P_{A C, \text { shuntVSC }}=P_{D C, \text { shuntVSC } \text { and }} P_{D C, \text { seriesVSC }}=P_{A C, \text { seriesVSC }}
$$

That can be expanded as

$$
\begin{aligned}
& \frac{3}{2}\left(v_{\text {shcd }} i_{\text {shcd }}+v_{\text {shcq }} i_{s h c q}\right)=v_{d c} i_{d c s h} \\
& v_{d c} i_{d c s r}=\frac{3}{2}\left(v_{s r c d} i_{s r c d}+v_{s r c q} i_{s r c q}\right)
\end{aligned}
$$

where

$$
i_{d c s h}=i_{R_{d c h}}+i_{C_{d c}}+i_{R_{d c s}}+i_{d c s r}
$$

Therefore, the relation between AC power and DC power can be expressed as

$$
\begin{aligned}
\frac{d v_{d c}}{d t}= & -\frac{1}{C_{d c} R_{d c s h}} v_{d c}-\frac{1}{C_{d c} R_{d c s r}} v_{d c}+\frac{3}{2} \frac{1}{C_{d c} v_{d c}} v_{\text {shcd }} i_{\text {shcd }}+\frac{3}{2} \frac{1}{C_{d c} v_{d c}} v_{s h c q} i_{\text {shcq }} \\
& -\frac{3}{2} \frac{1}{C_{d c} v_{d c}} v_{s r c d} i_{s r c d}-\frac{3}{2} \frac{1}{C_{d c} v_{d c}} v_{s r c q} i_{s r c q}
\end{aligned}
$$

where $v_{s r c d}$ and $v_{s r c q}$ represent the output voltages in $d$ and $q$ axes of series VSC. The series VSC output voltage can be controlled by the control signal that the $v_{s r c d}$ and $v_{s r c q}$ can be expanded by $v_{s r c d}=k_{p} u_{s r d} v_{d c}$ and $v_{s r c q}=k_{p} u_{s r q} v_{d c}$. While $u_{s r d}$ and $u_{s r q}$ are the control signals of series VSC. The series VSC output currents in $d$ and $q$ axes are represented by $i_{s r c d}$ and $i_{s r c q}$, respectively. $C_{d c}$ is the DC link capacitor whereas the resistor $R_{d c s h}$ and $R_{d c s r}$ represent losses in the shunt and series VSCs, respectively.

\subsection{Equations at the series VSC side}

$$
\begin{aligned}
& \frac{d i_{s r c d}}{d t}=-\frac{R_{s r}}{L_{s r}} i_{s r c d}+\frac{1}{L_{s r}} v_{s r c d}-\frac{1}{L_{s r}} v_{s r d}+\omega i_{s r c q} \\
& \frac{d i_{s r c q}}{d t}=-\frac{R_{s r}}{L_{s r}} i_{s r q}+\frac{1}{L_{s r}} v_{s r c q}-\frac{1}{L_{s r}} v_{s r q}-\omega i_{s r c d} \\
& \frac{d v_{s r d}}{d t}=\frac{1}{C_{s r}} i_{s r c d}-\frac{1}{C_{s r}} i_{l d}+\omega v_{s r q} \\
& \frac{d v_{s r q}}{d t}=\frac{1}{C_{s r}} i_{s r q}-\frac{1}{C_{s r}} i_{l q}-\omega v_{s r d} \\
& \frac{d i_{L d}}{d t}=\frac{1}{L_{l}} v_{l d}+\omega i_{L l q} \\
& \frac{d i_{L q}}{d t}=\frac{1}{L_{l}} v_{l q}-\omega i_{L l d}
\end{aligned}
$$


where the $v_{s r d}$ and $v_{s r q}$ are the voltages at series transformer in $d$ and $q$ axes, while the $i_{L l d}$ and $i_{L l q}$ are currents flow into the inductor load in $d$ and $q$ axes. The load bus voltages in $d$ and $q$ axes are represent by $v_{l d}$ and $v_{l q}$ , respectively. The $v_{l d}$ and $v_{l q}$ can be expanded as

$$
\begin{gathered}
v_{l d}=v_{s h d}+v_{s r d} \\
v_{l q}=v_{s h q}+v_{s r q}
\end{gathered}
$$

In this paper, the voltage at PCC is selected as a reference voltage. This implies that

$$
v_{s h q} \equiv 0 \text { and } \frac{d v_{s h q}}{d t}=0
$$

Defining angle between reference voltage and infinite bus voltage as $\alpha=\theta-\omega_{s} t$, where $\omega_{s}$ is the angular speed of the infinite bus phase voltage. The equation for this choice of reference frame can be expressed as:

$$
\frac{d \alpha}{d t}=\omega-\omega_{s}
$$

where $\omega=\frac{d \theta}{d t}$ is a function of time. The angular speed of the reference voltage $(\omega)$ can be obtained by using (4) that is

$$
\omega=\frac{-i_{l q}+i_{s q}-i_{s h c q}}{C_{s h} v_{s h d}}
$$

where the $\omega$ varies with time and it is different from $\omega_{s}$.

\section{CONTROL SYSTEM OF UPQC}

\subsection{Control strategy of series VSC}

In this paper, the main objectives of employing UPQC in solving power quality in distribution system are to maintain bus voltage regulation (AC voltage control) and power factor correction (PF control).The series VSC is applied to completely solve the bus voltage regulation and the power factor correction. The bus voltage control is achieved by inserting the voltage by the series VSC into the system. In addition, the series VSC is also used to correct the load power factor by injecting the reactive power into the system at the PCC. The control strategy of the series VSC is shown in Figure 3(a). As can be seen in this figure, the controls of series VSC consist of the AC voltage control and PF control as an outer loop and hysteresis current control as an inner loop. In addition, a phase locked loop (PLL) is employed to synchronize with the reference voltage at PCC. The output of the PLL $(\theta)$ is used for $a b c$-to- $d q 0$ and $d q 0$-to-abc transformation. 


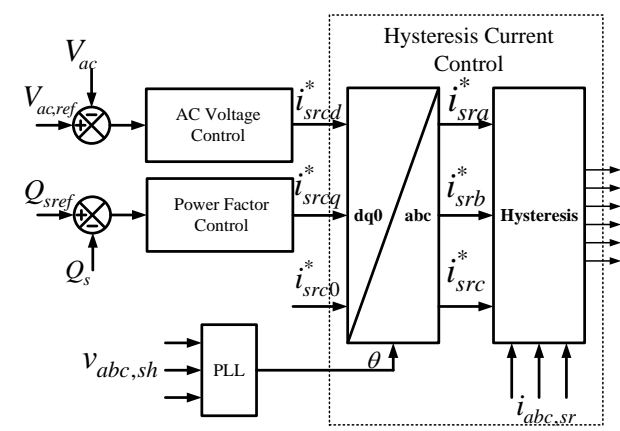

(a)

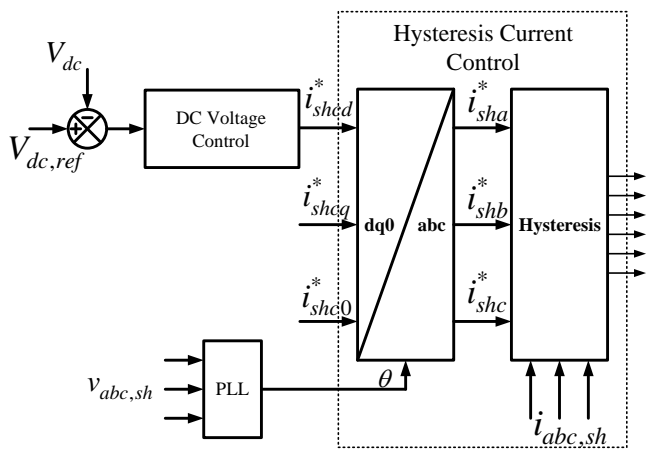

(b)

Figure 3. Control scheme of series and shunt VSC

\subsection{Control strategy of shunt VSC}

Meanwhile the series VSC is used to regulate bus voltage, the shunt VSC is employed to prepare the real power for series VSC. This power is transferred to the series VSC through the DC link. In this function, the DC voltage control has to be necessary for the shunt VSC. Furthermore, the DC voltage must be controlled at the desire value for along with the UPQC operation. In order to control the DC voltage, the real power flowing though the shunt VSC into the DC capacitor is adjusted which compensates the losses of shunt VSC and keeps the DC voltage constant. This power is adjusted by changing the reference current in $d$ axis. The control strategy of the shunt VSC is shown in Figure 3(b). In this figure, the DC voltage is an outer loop whereas hysteresis current control is an inner loop. Similar to the series VSC control, the PLL is also used for $a b c$-to- $d q 0$ and $d q 0$-to- $a b c$ transformation in the shunt VSC control as well.

As can be seen in Figure 3(a) and 3(b), the hysteresis current control is applied in the inner loop of the UPQC control. The $d q$ reference currents obtained by the outer loop controllers are transformed to $a b c$ reference currents and then they are given to the hysteresis current control to compare with the sensed three phases actual VSC currents. The output of the hysteresis current control is a set of six switching signals to switches the VSC. The hysteresis current control is popular used in VSCs control [11]-[12] because it gives fast respond and high accuracy. However, in practical, the hysteresis current control has a small time delay $\left(T_{e}\right)$ in accordance with the time delay of current measuring and digital signal processing. With the characteristic of hysteresis current control, the reference currents can be tacked by the actual VSC currents with a small time delay. Therefore, the closed loop of the hysteresis current control of the shunt and series VSC can be written as follows:

$$
\begin{gathered}
\frac{d i_{s h c d}}{d t}=\frac{1}{T_{e}} i_{s h c d}^{*}-\frac{1}{T_{e}} i_{s h c d} \\
\frac{d i_{s h c q}}{d t}=\frac{1}{T_{e}} i_{s h c q}^{*}-\frac{1}{T_{e}} i_{s h c q} \\
\frac{d i_{s r c d}}{d t}=\frac{1}{T_{e}} i_{s r c d}^{*}-\frac{1}{T_{e}} i_{s r c d} \\
\frac{d i_{s r c q}}{d t}=\frac{1}{T_{e}} i_{s r c q}^{*}-\frac{1}{T_{e}} i_{s r c q}
\end{gathered}
$$

where $i_{s h c d}^{*} i_{s h c q}^{*} i_{s r c d}^{*}$ and $i_{s r c q}^{*}$ are the $d q$ reference currents of the shunt and series VSCs. With an appropriate hysteresis current control, the behavior of VSCs currents in (5)-(6) and (8)-(9) can be replaced by the closed loop current control as in (15)-(16) and (17)-(18), respectively. Furthermore, the relation between AC power and DC power in (7) can be modified as follows: 


$$
\begin{aligned}
\frac{d v_{d c}}{d t}= & -\frac{1}{C_{d c} R_{d c s h}} v_{d c}+\frac{3}{2} \frac{1}{C_{d c} v_{d c}} v_{s h d} i_{s h c d}+\frac{3}{2} \frac{1}{C_{d c} v_{d c}} v_{s h q} i_{s h c q} \\
& -\frac{1}{C_{d c}}\left(\frac{1}{R_{d c s r}} v_{d c}+\frac{3}{2} \frac{1}{v_{d c}} v_{s r d} i_{s r c d}+\frac{3}{2} \frac{1}{v_{d c}} v_{s r q} i_{s r c q}\right)
\end{aligned}
$$

Equation (19) describes the relationship of power between the AC and DC power, regardless the impact of connected resistance and inductance of both shunt and series VSC. So the output voltages of converter $\left(v_{\text {shcd }}, v_{\text {shcq }}, v_{\text {srcd }}\right.$ and $\left.v_{\text {srcq }}\right)$ can be replaced by the output voltages of transformer $\left(v_{\text {shd }}, v_{\text {shq }}, v_{\text {srd }}\right.$ and $\left.v_{s r q}\right)$. In addition, equation (19) is the DC voltage whereas the AC voltage and reactive power of electrical source can be described as (20) and (21), respectively.

$$
\begin{aligned}
& \frac{d v_{L}}{d t}=\frac{1}{T_{e}} \sqrt{v_{l d}^{2}+v_{l q}^{2}}-\frac{1}{T_{e}} v_{L} \\
& \frac{d Q_{s}}{d t}=\frac{1}{T_{e}} \frac{3}{2} \frac{1}{C_{d c} v_{d c}} v_{\text {shd }} i_{\text {shcd }}+\frac{3}{2} \frac{1}{C_{d c} v_{d c}} v_{s h q} i_{s h c q}-\frac{1}{T_{e}} Q_{s}
\end{aligned}
$$

where $v_{L}$ is the AC voltage and $Q_{s}$ is the source reactive power.

\section{DYNAMICS SYSTEM ANALYSIS}

It is well known that the dynamics of distribution system with the UPQC can be described by nonlinear differential equation system. However, the nonlinear system can be approximated by linearization around certain operating conditions. The linearization models can be used to analyze the dynamic performance of the distribution system with the UPQC.

\subsection{Linearization and transfer function}

A mathematical model of the distribution system with the UPQC that is found in (1)-(3) and (10)(21) are used for obtain the transfer function of control systems. However, these equations are nonlinear differential equations. To analyze dynamic performance of the control system, linear approximation technique that described in [13] is applied. This technique gives a set of linear equations as shown in (22).

$$
\Delta \dot{x}(t)=\left\{\frac{\partial f}{\partial x}\left(x_{0}, u_{0}\right)\right\} \Delta x(t)+\left\{\frac{\partial f}{\partial u}\left(x_{0}, u_{0}\right)\right\} \Delta u(t)
$$

The partial derivatives in the linearization are evaluated at the initial points. The coefficients $A_{0}$ and $B_{0}$ can be solved and expressed as (23)-(24). Therefore the linearized system of the dynamic system can be represented as $(25)$.

$$
\begin{aligned}
& A_{0}=\frac{\partial f}{\partial x}\left(x_{0}, u_{0}\right) \\
& B_{0}=\frac{\partial f}{\partial u}\left(x_{0}, u_{0}\right) \\
& \Delta \dot{x}(t)=A_{0} \Delta x(t)+B_{0} \Delta u(t)
\end{aligned}
$$

where the state of the system is 
$\Delta x(t)=\left[\begin{array}{lllllllllllllll}\Delta i_{s d} & \Delta i_{s q} & \Delta v_{s d} & \Delta i_{\text {Ld }} & \Delta i_{\text {Lqq }} & \Delta \alpha & \Delta v_{d c} & \Delta i_{\text {shcd }} & \Delta i_{\text {shcq }} & \Delta i_{\text {srcd }} & \Delta i_{s r c q} & \Delta v_{\text {srd }} & \Delta v_{\text {srq }} & \Delta v_{L} & \Delta Q_{s}\end{array}\right]^{T}$

and the control input is

$$
\Delta u(t)=\left[\begin{array}{llll}
\Delta i_{\text {srcd }}^{*} & \Delta i_{\text {srcq }}^{*} & \Delta i_{\text {shcd }}^{*} & \Delta i_{\text {shcq }}^{*}
\end{array}\right]^{T}
$$

The output of system is can be expressed as:

$$
\Delta y(t)=C \Delta x(t)+D \Delta u(t)
$$

where

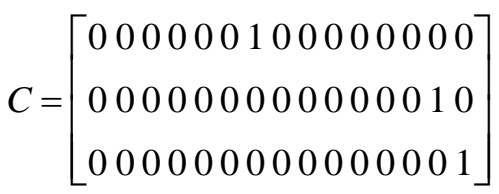

And in this case

$$
D=[0]_{(3 \times 4)}
$$

The MIMO transfer functions of the systems can be obtained by using equation (31).

$$
P(s)=C\left(s I-A_{0}\right)^{-1} B_{0}+D
$$

where $I$ is $15 \times 15$ identity matrix.

The control objectives of the distribution system with the UPQC are to regulate the DC voltage, AC bus voltage and to control the source reactive power as a zero (PF control). To analyze the DC voltage control, the DC voltage $\Delta v_{d c}$ is chosen as the output of the system with the active current command of the shunt VSC $\Delta i_{s h c d}^{*}$ as the control input. Similarly, to analyze the AC bus voltage control, the AC bus voltage $\Delta v_{L}$ is chosen as the output of the system with the active current command of the series VSC $\Delta i_{s r c d}^{*}$ as the control input. Meanwhile, the source reactive power $\Delta Q_{s}$ is chosen as the control output with the reactive current command of the shunt VSC $\Delta i_{\text {shcq }}^{*}$ as the control input for analysis the PF control.

\subsection{Bode plot analysis}

To illustrate the dynamic performance of the control systems, the data of distribution system and UPQC parameters as shown in Table 1 are used. The bode plots of the open loop transfer function of DC voltage control, AC bus voltage control and PF control are shown in Figure 4. As can be seen in this figure, the DC voltage control behavior is similar to the first order system with very large time constant.This system easy to design and tuning the controller because of the system has large gain and phase margin. 
Table 1. Data of distribution system and UPQC

\begin{tabular}{lc}
\hline Nominal source voltage $\left(V_{s}\right)$ & $22 \mathrm{kV}$ \\
Source and line resistance $\left(R_{s}\right)$ & $0.1 \Omega$ \\
Source and line inductance $\left(L_{s}\right)$ & $10 \mathrm{mH}$ \\
Resistance load $\left(R_{l}\right)$ & $80 \Omega$ \\
Inductance load $\left(L_{l}\right)$ & $500 \mathrm{mH}$ \\
Shunt and series filtering capacitances $\left(C_{s h}\right.$ and $\left.C_{s r}\right)$ & $10 \mu \mathrm{F}$ \\
Shunt and series DC resistance $\left(R_{d c s h}\right.$ and $\left.R_{d c s r}\right)$ & $20 \mathrm{k} \Omega$ \\
Nominal DC voltage $\left(V_{d c}\right)$ & $4 \mathrm{kV}$ \\
DC capacitance $\left(C_{d c}\right)$ & $2,000 \mu \mathrm{F}$ \\
\hline
\end{tabular}

Meanwhile, the AC voltage control and PF control are more difficult than the DC voltage control because both AC voltage control and PF control systems have higher gain and their behaviors are a higher order system as can be seen in the bode plot in Figure 4. The slight increase in gain of the controller can cause the AC voltage control and PF control system instability. Therefore, the controller design and parameters tuning of both $\mathrm{AC}$ voltage control and $\mathrm{PF}$ control systems should be carefully considered. So, to prevent the problems mentioned above, the controller design of the DC voltage, AC voltage, and PF control should be considered at the same time. Parameters of these controllers should be carefully tuned as well.

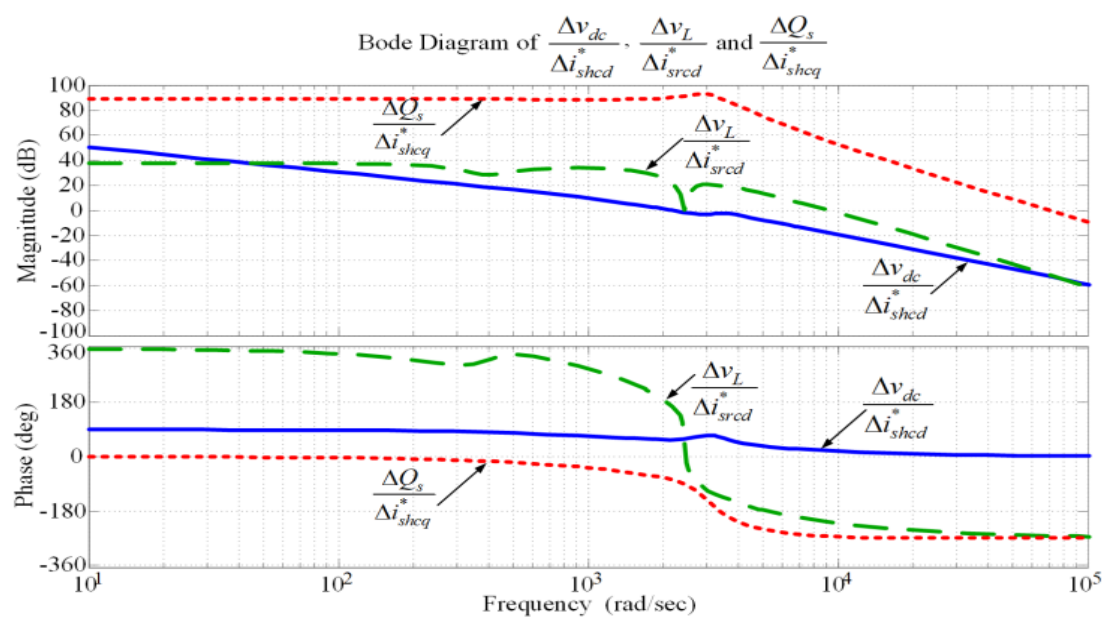

Figure 4. Bode plots of the open loop transfer function of DC voltage control, AC bus voltage control and PF control

In this paper, the PI controller is used to control AC voltage, DC voltage, and power factor which they are outer loop controls of the UPQC. The controller design of MIMO system is proposed in this paper. Two controller design techniques are presented and compared. One is the sequential loop closure controller design with parameter tuning through the bode diagram (SLC-BD). The other one is the controller optimization design with the genetic algorithms (CO-GA).

\section{SEQUENTIAL LOOP CLOSURE TECHNIQUE WITH BODE DIAGRAM (SLC-BD)}

In the MIMO system, if the transfer function matrix $\mathbf{P}(\mathbf{s})$ does not have an only diagonal member that means the system have a connection between the channels. It may be found that the design of the controllers in each channel is independent of each other and the closed loop control of each channel might have a good response. This section presents the design using a classical technique approach for designing the SISO system controller to design the controller of MIMO system. The controller of each channel must be 
designed and the control loop of each channel must be closed before the next channel control is designed. The characteristic of the controllers in the transfer function matrix format would be only the members in the diagonal of the matrix. The feature of each controller connected to the system $\mathbf{P}(\mathbf{s})$ is shown in Figure 5 . As can be seen in this figure, the output of the DC voltage, AC voltage and PF control can be expressed as follows.

$$
\begin{aligned}
& i_{s h c d}^{*}=f_{d c} K_{i d c}+\left(v_{d c}^{*}-v_{d c}\right) K_{p d c} \\
& i_{s r c d}^{*}=f_{a c} K_{i a c}+\left(v_{a c}^{*}-v_{a c}\right) K_{p a c} \\
& i_{s r c d}^{*}=f_{p f} K_{i p f}+\left(Q_{s}^{*}-Q_{s}\right) K_{p p f}
\end{aligned}
$$

where

$$
\begin{aligned}
& \frac{d f_{d c}}{d t}=\left(v_{d c}^{*}-v_{d c}\right) \\
& \frac{d f_{a c}}{d t}=\left(v_{a c}^{*}-v_{a c}\right) \\
& \frac{d f_{p f}}{d t}=\left(Q_{s}^{*}-Q_{s}\right)
\end{aligned}
$$

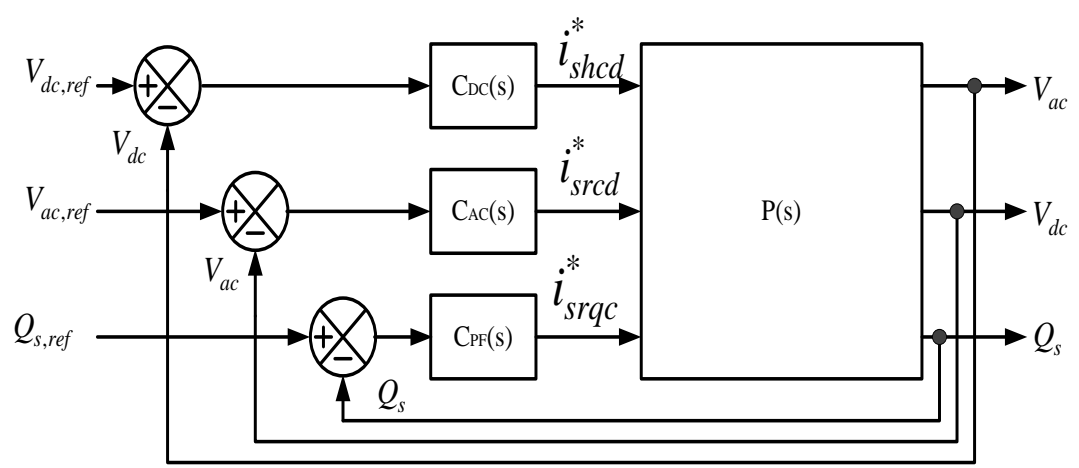

Figure 5. Feature of each controller connected to the control system

In this paper, the DC voltage, AC voltage and PF control are selected as the first, second, and the third control loop, respectively. The three-loop control design uses the PI controller with the parameters ( $K_{p d c}, K_{i d c}, K_{p a c}, K_{i a c}, K_{p p f}$, and $K_{i p f}$ ) tuning based on classical technique such as the bode diagram. By selecting the stability margins such as the magnitude and phase margins of each control loop at approximately $6 \mathrm{~dB}$ and $60 \mathrm{deg}$, respectively, sufficient for each control loop to have robust control features [15]. The parameters and the stability margins of three controllers are shown in Table 2. However, when all the three control loops work together in the same time, the properties of these control loops are changed as shown in Table 3.

Table 2. Parameters of DC, AC, and PF control by SLC-BD

\begin{tabular}{lcccc}
\hline \multicolumn{1}{c}{ Controllers } & $\mathrm{GM}(\mathrm{dB})$ & $\mathrm{PM}(\mathrm{deg})$. & $\mathrm{K}_{\mathrm{p}}$ & $\mathrm{K}_{\mathrm{i}}$ \\
\hline DC Voltage Controller & 6.03 & 58.47 & -0.70 & -43.00 \\
AC Voltage Controller & 6.04 & 60.33 & 0.07 & 5.50 \\
PF Controller & 6.07 & 60.14 & 0.00 & 0.05 \\
\hline
\end{tabular}


Table 3. Comparison of gain and phase margin of DC, AC, and PF control

\begin{tabular}{lcccc}
\hline \multicolumn{1}{c}{ Controllers } & \multicolumn{2}{c}{ Design } & \multicolumn{2}{c}{ Working } \\
& $\mathrm{GM}(\mathrm{dB})$ & $\mathrm{PM}(\mathrm{deg})$. & $\mathrm{GM}(\mathrm{dB})$ & $\mathrm{PM}(\mathrm{deg})$. \\
\hline DC Voltage Controller & 6.03 & 58.47 & 4.02 & 44.39 \\
AC Voltage Controller & 6.04 & 60.33 & 4.05 & 41.38 \\
PF Controller & 6.07 & 60.14 & 5.53 & 52.28 \\
\hline
\end{tabular}

As can be seen in Table 3 that shows the comparison of the magnitude and phase margins of each control loop when each control loop is designed independent of each other and when all the three control loops work together. It was found that the margins of all the three control loops decreased when working together in the same time. As a result, the responses of theses control loops are poor.

\section{PI CONTROLLER OPTIMIZATION BY USING GENETIC ALGORITHMS (CO-GA)}

In this section, the design of the controller has been developed by design and tuning of all the three PI controller's parameters at the same time. There are many different methods for tuning the PI controller parameters. In the proposed method, the PI controller parameters must be tuned to improve the respond and dynamic stability of the control system. This study employs the GA to improve optimization synthesis and obtained the global optimum value of the objective function. To perform the optimization properly, its objective function is the key.

\subsection{Objective function formulation}

The optimal objective function can be considered from a constrained optimization problem as follows.

Minimize $f(x)$

Subject to $g(x)=0$, equality constraints

$h(x) \leq 0$, inequality constraints

In this paper, the penalty method as described in [16] is used. The both equality and inequality constraints can be converted into penalty terms. The constrained optimization problem is transformed into an unconstrained optimization problem. Therefore the penalty function can be obtained as described in (38) and (39).

$$
\begin{aligned}
& P(x)=f(x)+\Omega(x) \\
& \Omega(x)=\rho\left\{g^{2}(x)+\left[\max (0, h(x)]^{2}\right\}\right.
\end{aligned}
$$

where

$P(x)$ is the penalty function

$\Omega(x)$ is the penalty term

$\rho$ is the penalty factor

The optimal problem in this section consists of a nonlinear objective function defined with nonlinear constraints. The objective function use herein is to minimize the summation of the difference between the desired values and the responses of three control loops by optimizing their PI controllers. The objective function is shown as equation (40).

$$
\operatorname{Mini} f(x, u)=\sum_{0}^{t_{\text {sim }}}\left(\left(\Delta_{d c}(t)\right)^{2}+\left(\Delta v_{a c}(t)\right)^{2}+\left(\Delta Q_{s}(t)\right)^{2}\right)
$$

where

$$
\begin{aligned}
& \Delta v_{d c}=v_{d c}^{\text {desired }}-v_{d c}^{\text {simulated }} \\
& \Delta v_{a c}=v_{a c}^{\text {desired }}-v_{a c}^{\text {simulated }} \\
& \Delta Q_{s}=Q_{s}^{\text {desired }}-Q_{s}^{\text {simulated }}
\end{aligned}
$$


The $v_{d c}^{\text {desired }} v_{d c}^{\text {desired }}$, and $Q_{s}^{\text {desired }}$ are the desired values of DC voltage, AC voltage and source reactive power, respectively. The $v_{d c}^{\text {simulated }}, v_{a c}^{\text {simulated }}$, and $Q_{s}^{\text {simulated }}$ are the simulated responses of DC voltage, AC voltage and source reactive power, respectively. Meanwhile, $x$ is the state of system, $u$ is variable change. In addition, the robust control feature of each control loop is considered in this section. Therefore, the magnitude and phase margins of all the three controls are used as the constraints to be formed as inequality constraints as shown below.

$$
\begin{gathered}
G M_{d c}^{\min } \leq G M_{d c} \\
G M_{a c}^{\min } \leq G M_{a c} \\
G M_{p f}^{\min } \leq G M_{p f} \\
P M_{d c}^{\min } \leq P M_{d c} \\
P M_{a c}^{\min } \leq P M_{a c} \\
P M_{p f}^{\min } \leq P M_{p f}
\end{gathered}
$$

where

$G M_{d c}$ and $P M_{d c}$ are the gain and phase margins of the DC voltage control.

$G M_{a c}$ and $P M_{a c}$ are the gain and phase margins of the AC voltage control.

$G M_{p f}$ and $P M_{p f}$ are the gain and phase margins of the power factor control.

The subscribe min means the minimum value of gain and phase margins that the control loop to has the robust control feature. The penalty function this problem can be formulated as follows.

$$
P(x)=f(x, u)+\Omega_{G M}+\Omega_{P M}
$$

where:

$$
\begin{aligned}
& \Omega_{G M}=\rho\left\{\max \left(0, G M_{d c}-G M_{d c}^{\min }\right)\right\}^{2}+\rho\left\{\max \left(0, G M_{a c}-G M_{a c}^{\min }\right)\right\}^{2}+\rho\left\{\max \left(0, G M_{p f}-G M_{p f}^{\min }\right)\right\}^{2} \\
& \Omega_{P M}=\rho\left\{\max \left(0, P M_{d c}-P M_{d c}^{\min }\right)\right\}^{2}+\rho\left\{\max \left(0, P M_{a c}-P M_{a c}^{\min }\right)\right\}^{2}+\rho\left\{\max \left(0, P M_{p f}-P M_{p f}^{\min }\right)\right\}^{2}
\end{aligned}
$$

\subsection{Controller optimization with genetic algorithm (CO-GA)}

In exist of many articles [17]-[19], the GA technique is applied to design the controller in various forms. The GA is a population based search technique that generates a set of population in solution space evolved using the principles of genetic evolution and natural selection, called genetic operators e.g. crossover, mutation, etc. With successive updating new generation, a set of updated solutions gradually converges to the real solution. In this paper, the GA is employed to build up an algorithm to tune PI parameters of the DC voltage, AC voltage and PF control ( $K_{p d c}, K_{i d c}, K_{p a c}, K_{i a c}, K_{p p f}$, and $\left.K_{i p f}\right)$. The COGA procedures can be explained briefly as shown in the flowchart of Figure6.The procedure of the PI controller parameter tuning based on GA is described as follows. First, the parameters of GA and distribution system are specified. Second, the GA generates a set of initial population for time-domain simulation. Then, the time-domain results of the fitness of each individual are obtained by simulating the DC voltage, AC voltage and PF control system in MATLAB program. With the searching process, the PI controller parameters are adjusted to give response of best fitting close to the desired response. 


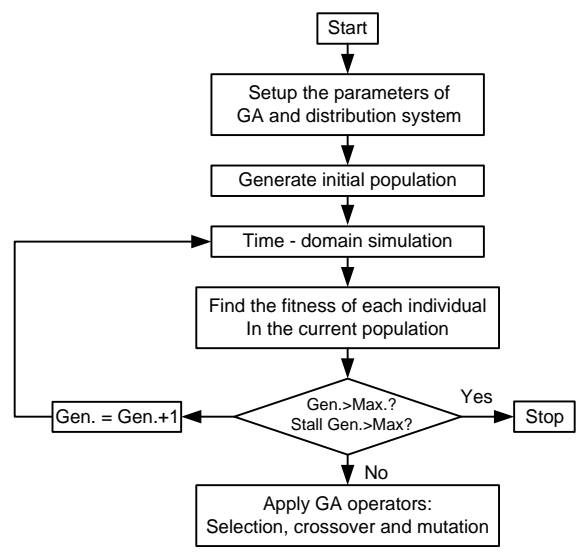

Figure 6. Flowchart of the GA procedures

\section{RESULTS AND DISCUSSIONS}

\subsection{Results of CO-GA}

In this section, the results of the PI controller parameter tuning based on the GA are proposed. The best PI controller parameters are obtained with 50 computational trials in test case. The best controller parameters, fitness value and the stability margins in operating condition are shown in Table 4. As can be seen in this table, gain margins and phase margins in this operating condition are more than $6 \mathrm{~dB}$ and $60 \mathrm{deg}$, respectively.

Table 4. Parameters of DC, AC, and PF controller by CO-GA

\begin{tabular}{cccccc}
\hline Controllers & $\mathrm{K}_{\mathrm{p}}$ & $\mathrm{K}_{\mathrm{i}}$ & $\mathrm{GM}(\mathrm{dB})$ & $\mathrm{PM}(\mathrm{deg})$ & Fitness \\
\hline DC Voltage Controller & -0.3049 & -0.0009 & $\infty$ & 66.817 & \\
AC Voltage Controller & 0.0292 & 5.0735 & 19.291 & 68.848 & 34,347 \\
PF Controller & 0.0000 & 0.0299 & 7.6048 & 61.401 & \\
\hline
\end{tabular}

The step responds of the DC voltage control, AC voltage control, and PF control with the parameter tuning based on the SLC-BD and CO-GA methods are compared as shown in Figure 7, 8, and 9, respectively. The comparisons show that the responds of all the three controls with the controller design based on CO-GA gives smaller oscillation and also smaller overshoot.

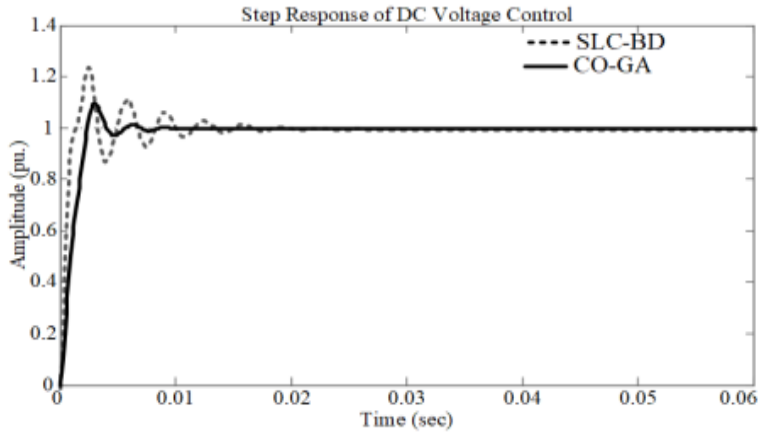

Figure 7. Step responds of the DC voltage control

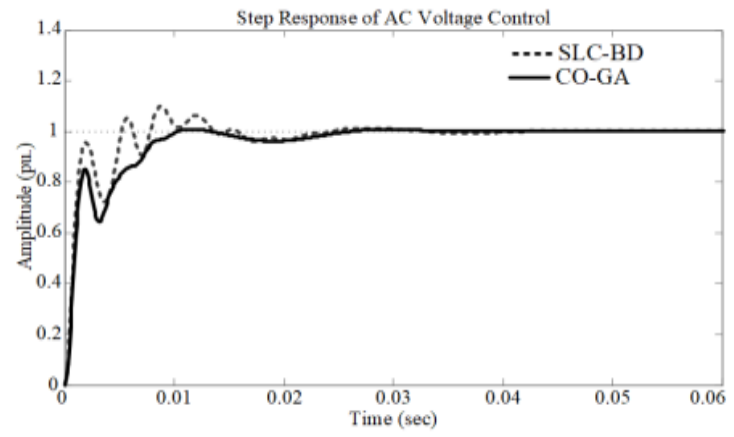

Figure 8. Step responds of the AC voltage control 


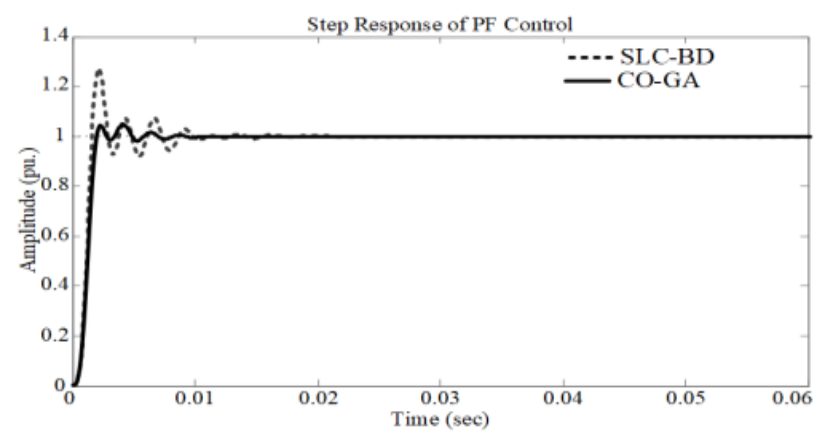

Figure 9. Step responds of the PF control

\subsection{Transient performance analysis and comparison}

To verify the effectiveness and performance of the proposed controller design, the distribution system with left-shunt UPQC and its control was formulated and therefore simulated in MATLAB program. Three cases such as 1) applying $10 \%$ of source voltage sag, 2) applying $30 \%$ of source voltage sag, and 3) applying $30 \%$ of source voltage swell are tested in this paper.

In case 1 , decreasing $10 \%$ of the source voltage is applied at $t=0.2 \mathrm{sec}$. The responses of three controls such as the AC voltage, DC voltage, and PF controls are show in Figure 10. As can be seen in this figure, the dynamic responses of the designed controllers based on SLC-BD and CO-GA provide the same good performance because this case is operated nearly the normal operating point. They can reach the desired value with a small overshoot and oscillation within $0.01 \mathrm{sec}$.

In case 2 , decreasing $30 \%$ of the source voltage is applied at $t=0.6 \mathrm{sec} .-0.8 \mathrm{sec}$. For decreasing of the source voltage at $t=0.6$ sec., the responses of designed controller based on the CO-GA show a good performance and preferable stability margins whereas the designed controllers based on the SLC-BD gave a poor performance in this case. However, when the source voltage is become to be a normal voltage at $t=0.8$ sec., the responses of those controls based on both SLC-BD and CO-GA provide the same good performance. The dynamic responses in case 2 are shown in Figure 11.

Case 3 , the increasing $30 \%$ of source voltage at $t=1.00 \mathrm{sec}$. is tested in this case. The results of case 3 are shown in Figure 12. This figure compares the dynamic responses of the AC voltage, DC voltage, and $\mathrm{PF}$ control of the designed controller based on the CO-GA and SLC-BD. As a result, the responses of the designed controllers based on the CO-GA give better performances.

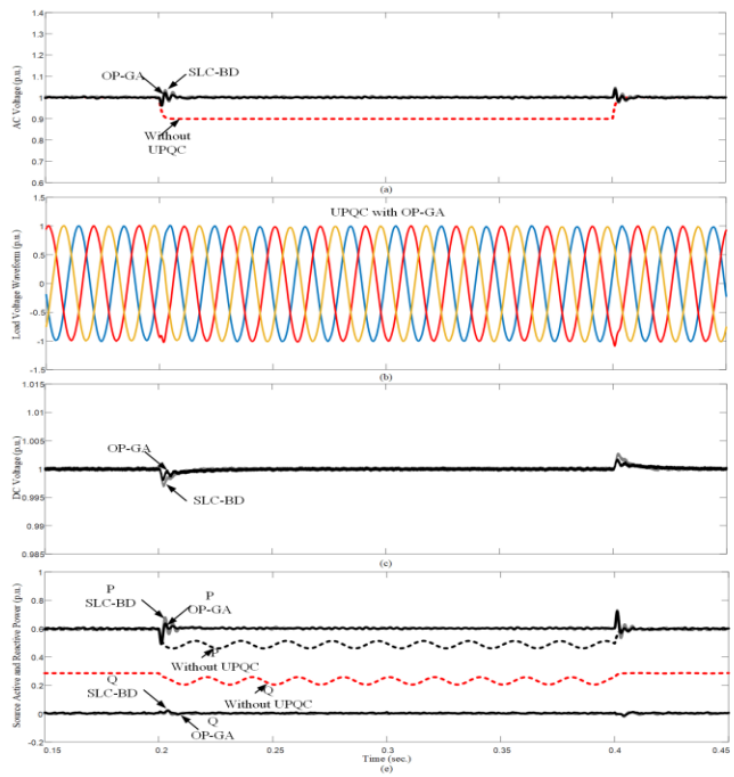

Figure 10. Dynamic responses of the AC voltage, $\mathrm{DC}$ voltage, and PF controls in case 1

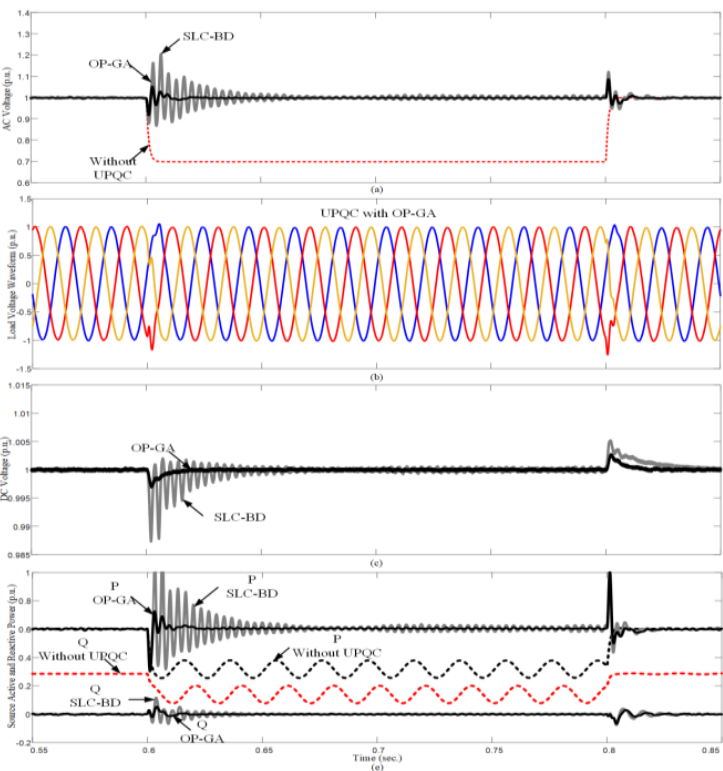

Figure 11. Dynamic responses of the AC voltage, DC voltage, and PF controls in case 2 


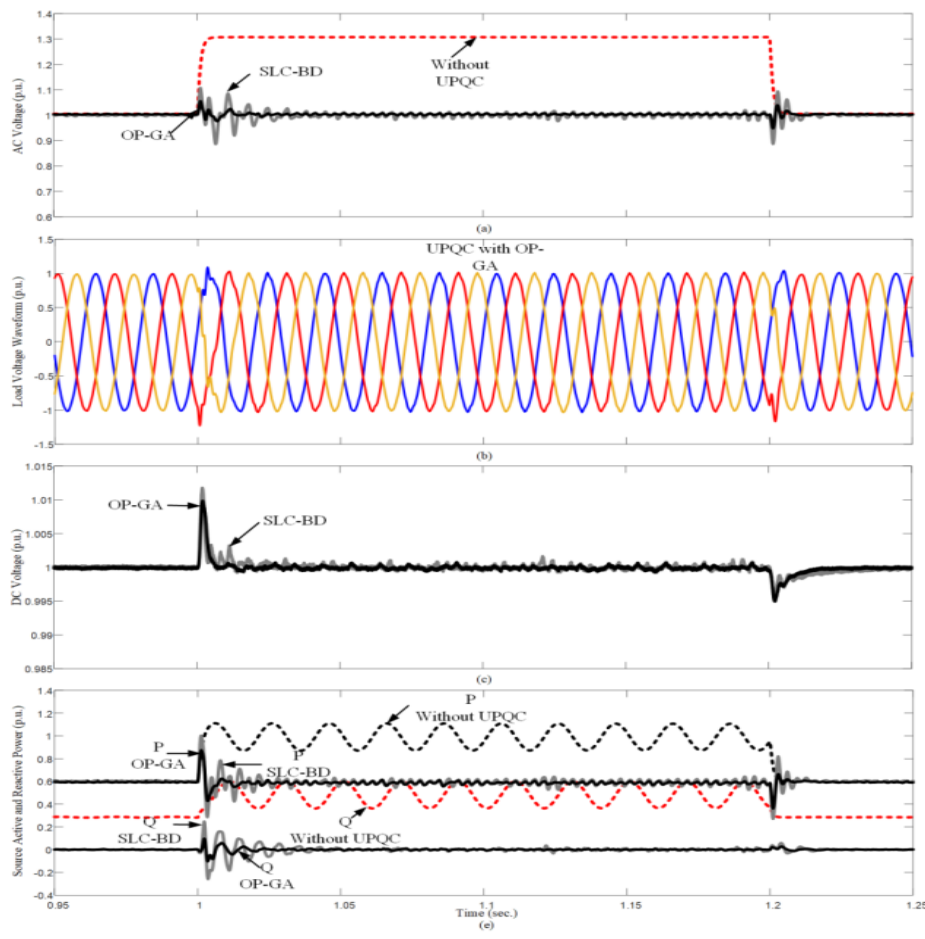

Figure 12. Dynamic responses of the AC voltage, DC voltage, and PF controls in case 3

\section{CONCLUSION}

This paper illustrates the procedure of controller design of UPQC for solving power quality problems such as voltage sag/swell and poor power factor in power distribution system. With the proposed completely mathematical model of the distribution system including UPQC and applying of linear approximation technique, the MIMO transfer function is obtained. The decentralized PI controllers which are tuned by two controller design techniques, namely the SLC-BD and CO-GA are proposed in this paper. These studies are verified by using MATLAB program. Simulation results show that the UPQC with its proposed PI controller can enhance power quality in the power distribution system. In addition, the results show that the designed controller based on SLC-BD can rather provide a good performance for small change of the operating point than greater change of the operating point. Fortunately, the designed controller based on COGA can provide good performance for both changes.

\section{REFERENCES}

[1] C. Prakash and N. Suparna, "Design and Simulation of Phase-Locked Loop Controller Based Unified Power Quality Conditioner Using Nonlinear Loads," International Journal of Power Electronics and Drive System (IJPEDS), vol/issue: 2(4), pp. 417-423, 2012.

[2] A. Ghosh and G. Ledwich, "Power quality enhancement using custom power devices," Kluwer Academic, 2002.

[3] H. Fujita and H. Akai, "The unified power quality conditioner: the integration of series- and shunt-active filters," IEEE Trans. Power Electron., vol/issue: 13(2), pp. 315-322, 1998.

[4] Y. K. Latha, et al., "Unified Power Quality Conditioner for Voltage Sag and Harmonic Mitigation of Nonlinear Loads," International Journal of Power Electronics and Drive System (IJPEDS), vol/issue: 1(1), pp. 65-74, 2011.

[5] B. Singh and P. Venkateswarlu, "A Simplified Control Algorithm for Three-Phase Four-Wire Unified Power Quality Conditioner,” Journal of Power Electronics, vol/issue: 10(1), pp. 91-96, 2010.

[6] V. Khadkikar, et al., "Steady state power flow analysis of unified power quality conditioner (UPQC)," International Conference on Industrial Electronics and Control Applications, Quito, pp. 1-6, 2005.

[7] S. A. Taher and S. A. Afsari, "Optimal Location and Sizing of UPQC in Distribution Networks Using Differential Evolution Algorithm," Mathematical Problems in Engineering, pp. 1-20, 2012.

[8] K. V. R. Reddy, et al., "Advance Technology in Application of Four Leg Inverters to UPQC," International Journal of Power Electronics and Drive System (IJPEDS), vol/issue: 7(4), pp. 1153-1160, 2016.

[9] K. R. Rao and K. S. Srikanth, "Improvement of Power Quality using Fuzzy Logic Controller in Grid Connected Photovoltaic Cell using UPQC," International Journal of Power Electronics and Drive System (IJPEDS), vol/issue: 5(1), pp. 101-111, 2014. 
[10] A. K. Maity, et al., "Design of a dynamic model of the unified power quality conditioner and its operation control," Proceedings of the 2015 Third International Conference on Computer, Communication, Control and Information Technology (C3IT), pp. 1-4, 2015.

[11] G. Wang and Y. W. Li, "Parabolic PWM for Current Control of Voltage-Source Converters (VSCs)," IEEE Transactions on Industrial Electronics, vol/issue: 57(10), pp. 3491-3496, 2010.

[12] P. Ajitha and D. Jananisri, "Voltage Sag Mitigation and Load Reactive Power Compensation by UPQC," Bulletin of Electrical Engineering and Informatics), vol/issue: 3(2), pp. 109-112, 2014.

[13] J. D'Azzo and H. Houpis, "Linear control system analysis and design: conventional and modern," McGraw-Hill, 1995.

[14] L. Fiorentini, et al., "Robust nonlinear sequential loop closure control design for an air-breathing hypersonic vehicle model," 2008 American Control Conference, Seattle, WA, pp. 3458-3463, 2008.

[15] P. Mercader, et al., "Robust proportional-integral-derivative design for processes with interval parametric uncertainty," IET Control Theory \& Applications, vol/issue: 11(7), pp. 1016-1023, 2017.

[16] P. Dutta and A. K. Sinha, "Voltage Stability Constrained Muti-Objective Optimal Power Flow using Particle Swarm Optimization," It International conference on Industrial and Information Systems, pp. 161-166, 2006.

[17] V. M. Mishra, et al., "Novel Optimization Technique for PI Controller Parameters of ac/dc PWM Converter using Genetic Algorithms," International Journal of Power Electronics and Drive System, vol/issue: 2(2), pp. 151-159, 2012.

[18] T. Kulworawanichpong, et al., "Dynamic parameter identification of induction motors using intelligent search techniques," The 24th IASTED Int. Conf. Modelling, Identification, and Control (MIC 2005), pp. 328-332, 2005.

[19] Y. Chen, et al., "Application of Improved Genetic Algorithm in PID Controller Parameters Optimization," TELKOMNIKA Indonesian Journal of Electrical Engineering, vol/issue: 11(3), pp. 1524-1530, 2013.

\section{BIOGRAPHIES OF AUTHORS}

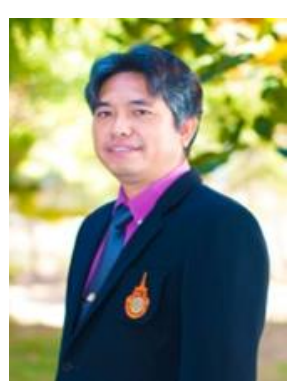

Kittaya Somsai is a lecturer of the Department of Electrical Engineering, Rajamangala University of Technology Isan (RMUTI) Sakon Nakhon Campus,Thailand. He received the B.Eng in Electrical Engineering from Rajamangala's Institute of Technology, Thailand (2003), M.Eng in Electrical Engineering from King Mongkut's Institute of Technology North Bangkok (KMITNB), Thailand (2005), and Ph.D. in Electrical Engineering from Suranaree University of Technology, Thailand (2012). His fields of research are interested in power systems, Custom Power Device (CPD), Flexible AC Transmission Systems (FACTS), power electronic and control, optimization and artificial intelligent techniques. 